\title{
視覚特性を考慮した高輝度光源の移動に伴う残像表現手法
}

\section{Perceptually Inspired Afterimage Synthesis for High-Intensity Moving Light Sources}

\author{
学生会員 三 鴨 道 弘 ${ }^{\dagger}$, \\ 正会員玉 木 徹柿, \\ Marcos Slomp ${ }^{\dagger \dagger}$,
}

Bisser Raytchev ${ }^{\dagger \dagger}$,

Michihiro Mikamo ${ }^{\dagger}$, Marcos Slomp $^{\dagger \dagger}$, Bisser Raytchev ${ }^{\dagger \dagger}$, Toru Tamaki ${ }^{\dagger \dagger}$ and Kazufumi Kaneda ${ }^{\dagger \dagger}$

\begin{abstract}
Afterimages are a common physiological phenomenon, typically caused by staring at bright light, such as the headlights of a car at night. This continuous trail of varying multicolored responses remains registered by the visual system, eventually fading out. Research on afterimages has been done for centuries, but real progress has been slow. Digital afterimage synthesis has been recently introduced to computer graphics. One of the few existing methods attempts to simulate the color and luminance transitions of afterimages using data from psychophysical and physiological experiments. Although this yields plausible results, the method is limited to still photographs. We extend this technique to the production of afterimages for moving, high-intensity light sources. This extension widens the range of applications that can benefit from the creative use of digital afterimages and should stimulate further research on the topic.
\end{abstract}

キーワード : 残像，視覚特性，色相変化，高輝度光源，時空間画像

\section{1. まえがき}

リアルな印象を与える画像の表示はコンピュータグラフィ クスにおいて，重要な課題のひとつであり，次の 2 点を考 慮する必要がある．物理現象に基づいた光学モデルと，心 理学・生理学現象に基づいた視覚特性モデルである. 特に 後者は, 眼に入射した光が受光体で電気信号に変換され，視 神経系に伝わり知覚されるまでの応答を模擬する。これに より，ディスプレイ表示された画像を現実世界の印象に近 づけることができる. 本論文で提案する手法は，後者のモ デルに属し, 心理物理学的な計測結果に基づく陽性残像表 現モデルである. 陽性残像は矓しい光を見た後に発生する 生理的な現象である。以下では単に残像と呼ぶ.

残像は自然科学や心理学・眼科学などで古くから研究の

2012 年 12 月 25 日受付, 2013 年 7 月 16 日再受付, 2013 年 9 月 12 日採録 †広島大学 大学院工学研究科 情報工学専攻

（空 739-8527 広島県東広島市鏡山 1-4-1 TEL 082-422-7111)

†鹿児島大学 大学院理工学研究科情報生体システム工学専攻

（广 890-0065 鹿児島市郡元 1-21-40 TEL 099-285-8453）

††広島大学 大学院工学研究院 情報部門

（预 739-8527 広島県東広島市鏡山 1-4-1 TEL 082-422-7111）

$\dagger$ Hiroshima University, Department of Information Engineering

(1-4-1 Kagamiyama, Higashi-hiroshima, 739-8527 JAPAN)

$\dagger \dagger$ Kagoshima University, Department of Engineering

(1-21-40 Korimoto, Kagoshima, 890-0065 JAPAN)

$\dagger \dagger \dagger$ Hiroshima University, Department of Information Engineering (1-4-1 Kagamiyama, Higashi-hiroshima, 739-8527 JAPAN)
対象となっている，例えば，ニュートンは太陽を見た後に 発生する残像を観察している ${ }^{1)}$. Weve は残像の色相変化を カラーネーミング法を用いて測定した ${ }^{2)}$ 。これによると，発 生する残像の色相は，異なる色相の光源であっても，時間 経過により同じような变化に近付くという知見を得た。ま た，Padgham は発生した残像が消えるまでの時間経過によ る輝度変化と色相変化を計測した ${ }^{3)}$ (図 1 参照).さらに, Reidenbach は Padgham ${ }^{4}$ と同様な実験を LED を用いて 行った ${ }^{5)}$ 。これによると, 残像の初期の色相は, 刺激となっ た光源の色相に近いという知見を得た.

コンピュータグラフィクス分野でも，残像を考慮するこ とにより，明暗の違いの大きさを意識させるリアルな画像 生成が注目を集めている. Ritschel らは錐体細胞内の才プ シンの濃度変化を基に残像が消える様子を表現した ${ }^{6)}$. し かし，この手法では残像の色相変化までは考慮されていな い.また，三鴨らは視覚の心理物理学分野での知見 ${ }^{2) 5)}$ と計 測結果 ${ }^{3) 4)}$ を利用することで, 静止する光源に対して色相変 化も表現できる残像生成モデルを開発した7). しかし，移 動する光源に対しては，その手法を適用できなかった。

本研究では，三鴨らの手法7)を拡張し，残像の色変化を 表現しながら, さらに，移動する光源にも適用可能な残像 表現モデルを提案する。これにより，夜間のドライビング シーンなどのより，一般的なシーンへの応用が可能となる. 


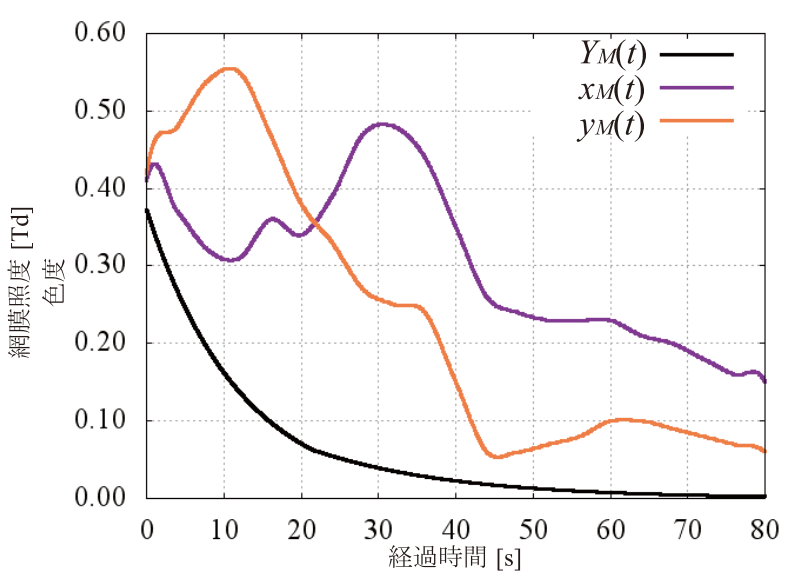

図 1 基潐光により発生する残像の輝度・色相変化 $(Y x y$ 表色 系で表示 $)^{3), 4)}$

Luminance and color transitions of afterimages (in the Yxy color space) according to the elapsed time as experienced and recorded by the article ${ }^{3), 4)}$, respectively.

\section{2. 提 案 手 法}

提案手法の基となる静止高輝度光源による残像表現モデ ル7をを簡単に説明する。この手法では基準光により発生す る残像の輝度・色相変化 (図 1) を基に寸る. そして, 様々 な光源色へ対応するため, 基準光と光源色の色差を加える. 高輝度光源が消灯した $t_{p}[\mathrm{~s}]$ 後における残像 $I(x, y)$ は次式 を用いて表される。

$$
\begin{aligned}
& I(x, y)_{L^{*}}=L_{M}^{*}\left(t_{p}\right) Z(x, y) \\
& I(x, y)_{a^{*}}= \\
& \quad a_{M}^{*}\left(t_{p}\right) Z(x, y)+k \cdot \tau_{M}\left(t_{p}\right) \Delta a^{*}(x, y) \\
& I(x, y)_{b^{*}}= \\
& \quad b_{M}^{*}\left(t_{p}\right) Z(x, y)+k \cdot \tau_{M}\left(t_{p}\right) \Delta b^{*}(x, y)
\end{aligned}
$$

ただし，添え字， $L^{*}, a^{*}, b^{*}$ は生成する残像の $L^{*}, a^{*}, b^{*}$ 成分を, $M$ は基準光による残像を, $\Delta a^{*}, \Delta b^{*}$ は残像を生 じさせる光源と基準光との色差を表す． $Z(x, y)$ は残像に 輝度分布を持たせるための係数である. $k, \tau_{M}\left(t_{p}\right)$ はそれ ぞれ文献 5) と文献 2)Weve25 による知見から, 光源の色を 残像に反映させる役割と, 時間経過により 0 に近づくこと で残像の色相を基準光による残像の色相に近づける役割を 持つ.

提案手法では高輝度光源の移動を考慮する．これにより 現実世界において，残像が移動する光源に対して軌跡を描 くように発生する様子を表現する。このような残像は各光 源位置に依存し, 発生時刻が異なる。これは, 光源移動が 起こる画素では, 移動直前・直後のフレームで, 光源が点 灯した状態から消灯した状態に遷移したとみることができ る。 そこで，画素位置 $(x, y)$ にある光源が，そこから移動 し存在しなくなった時刻を $t_{0}(x, y)$ とし, $t_{0}$ から現在時刻 $t_{A}$ までの経過時間を $t_{p}(x, y)$ とする. 提案手法では前提条 件として，光源は移動するが注視点は固定とする.

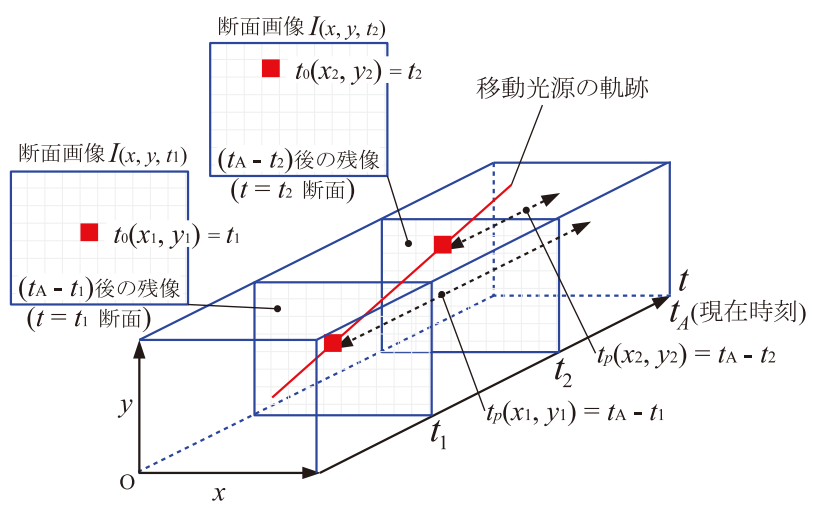

図 2 残像表現のための時空間画像

A Spatio-temporal image for the afterimage synthesis.

この考え方に基づき, 残像表現のための時空間画像 $I(x, y, t)$ (図 $\mathbf{2}$ 参照) を次式により生成する.

$$
\begin{aligned}
& I(x, y, t)_{L^{*}}=L_{M}^{*}\left(t_{p}(x, y)\right) Z(x, y) \\
& I(x, y, t)_{a^{*}}= \\
& \quad a_{M}^{*}\left(t_{p}(x, y)\right) Z(x, y)+k \cdot \tau_{M}\left(t_{p}(x, y)\right) \Delta a^{*}(x, y)
\end{aligned}
$$

$I(x, y, t)_{b^{*}}=$

$$
b_{M}^{*}\left(t_{p}(x, y)\right) Z(x, y)+k \cdot \tau_{M}\left(t_{p}(x, y)\right) \Delta b^{*}(x, y)
$$

ここで, $t_{p}(x, y)=\max \left(t_{A}-t_{0}(x, y), 0\right)$ である. 図 2 に 示寸ように, 高輝度光源が存在した画像位置 $(x, y)$ (移動光 源の軌跡と断面画像の交点である赤で示した画素) に，時 刻 $t_{0}(x, y)$ から残像が生成される. 生成された残像は現在 の時刻において, $t_{p}[\mathrm{~s}]$ 経過している.

この時空間画像を時間軸に沿って加え合わせることで, 時刻 $t_{A}$ に知覚される残像画像 $I_{A}(x, y)$ を得る.

$$
I_{A}(x, y)=\sum_{i=1}^{N} I\left(x, y, t_{i}\right)
$$

ここで, $N$ は時空間画像の枚数 $(\Delta t$ を時間サンプル間隔 とすると $\left.N=t_{A} / \Delta t\right)$ である. また，網膜が受ける刺激は 残像発生直後が最大であると考え, $I_{A}(x, y)$ の明度は最大 明度 $\left(L_{M}^{*}(0)\right)$ を超えないとする.

\section{3. 結 果 と考察}

図 3 に静止した光源による残像表示結果を示す。電球が 消灯した直後, 残像にはそれと同じような色相が現れるが, 時間経過とともに，異なる色相の電球による残像も同様な 色変化をする．このことは文献 2)〜5)の知見に合致して いる.

図 4 に移動する光源による残像表示結果を示す. 最も左 $(0[\mathrm{~s}])$ が発車直後であり, この瞬間からへッドライトが移 動する. 光源の軌跡に沿って残像が生じている様子が表現 できている．残像の色相はヘッドライトが通過してから経 過した時間に応じて変化していることがわかる. 寸なわち, ヘッドライト移動直後ほどヘッドライトの色相に近い黄色 い残像が現れており，発車直後の残像は緑ががかっている 


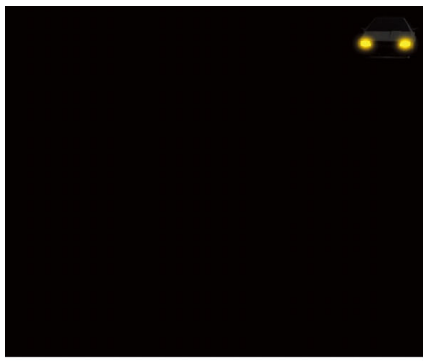

$0[\mathrm{~s}]$

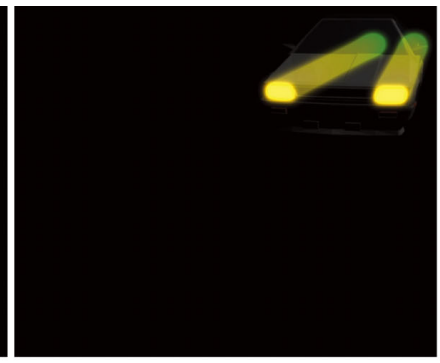

$5.3[\mathrm{~s}]$

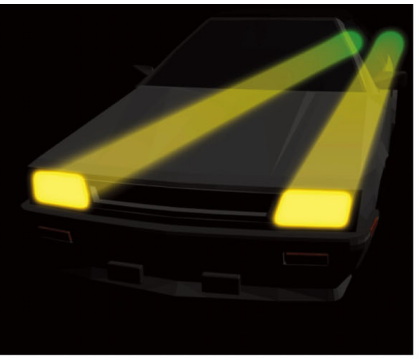

$6.4[\mathrm{~s}]$

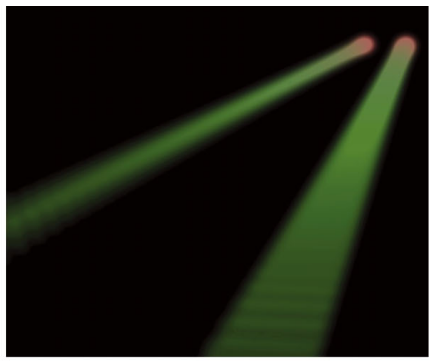

$24[\mathrm{~s}]$

図 4 移動光源による残像表示結果

Afterimage simulation of moving light sources.
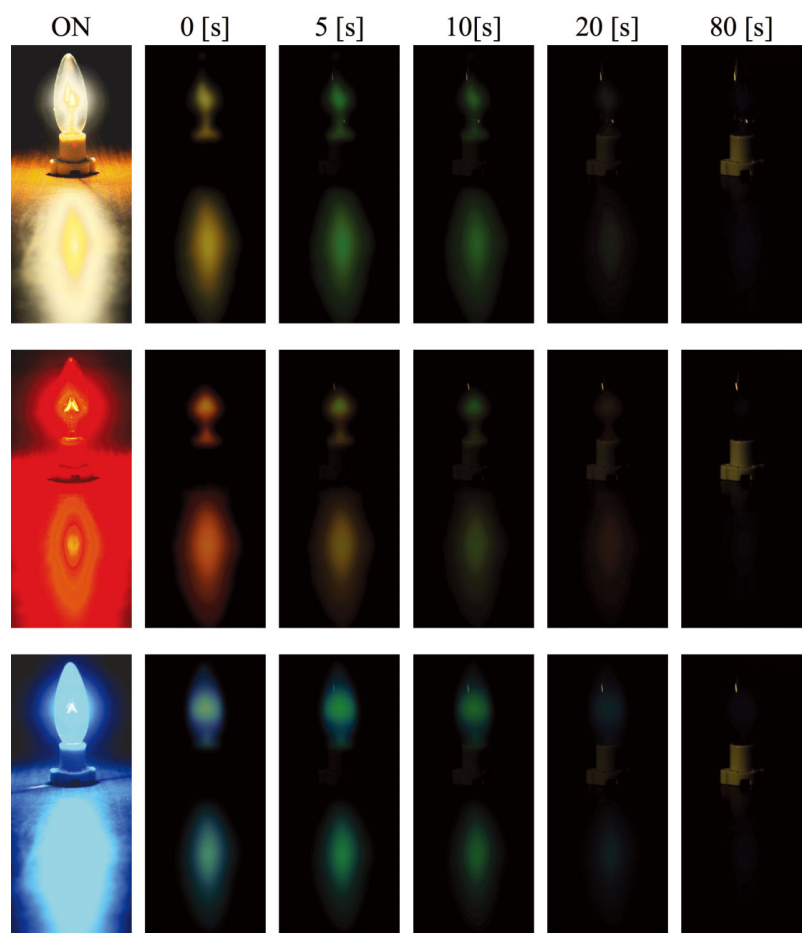

図 3 異なる光源による残像の色変化

Afterimage simulation of different colored light bulbs.

(6.4[s]). さらに時間が経過すると, 残像は全体に緑がかる $(24[\mathrm{~s}])$. これは図 3 に示した静止光源での残像の時間的色 相変化が、移動光源の軌跡に沿った空間的色相変化として 表れている。

\section{4. 結論と今後の課題}

本論文では, 残像の表現手法, 特に光源が移動した際に 起こる残像の表現方法を提案した. 光源移動を画素ごとの 光源点灯・消灯とみなし, さらに, 発生時間の時間差を考 慮することにより, 従来の静止光源に対する残像の表現を 拡張し, 移動光源による残像を表現することができた. 本 手法を用いて，車のヘッドライトによる残像を表現するこ とができた. そして, 表示結果は日常経験する残像と同じ ような特徴が現れていることを確認した.

提案手法は, エンターテインメント分野だけではなく, 将来的には交通標識などに使用される照明機器のデザイン や, 残像を知覚しやすい夜間を想定したドライビングシミュ レータなどへの応用も考えられる.

今後の課題として, 提案手法によって得られた残像画像
の心理物理学的な評価や検証が挙げられる. また, リアル タイムアプリケーションへの拡張がある.

\section{〔文献]}

1) R. S. Westfall: "Never at Rest: A Biography of Isaac Newton", Cambridge University Press, (1980)

2) H. Weve: "The Colours of After-images, following Strong Light Stimuli", British Journal of Ophthalmology, 9, 12, pp.627-638 (Dec. 1925)

3) C. A. Padgham: "Quantitative Study of Visual After-images", British Journal of Ophthalmology, 37, 3, pp.165-170 (Mar. 1953)

4) C. A. Padgham: "Measurements of the Colour Sequences in Positive Visual After-images", Vision Research, 8, 7, pp.939-949 (Jul. 1968)

5) H. D. Reidenbach: "Determination of the Time Dependence of Colored Afterimages", Proc. of SPIE The International Socety for Optical Engineering, 6844 (2008)

6) T. Ritschel and E. Eisemann: "A Computational Model of Afterimages", Proc. of Eurographics 2012, 31, 2, pp. 529-534 (May 2012)

7) M. Mikamo, M. Slomp, B. Raytchev, T. Tamaki and K. Kaneda: "Perceptually Based Afterimage Synthesis", Proc. of Eurographics 2012 (Short Papers), 31, 2, (May 2012)

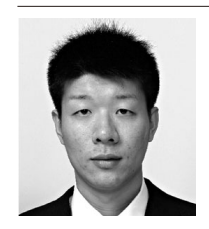

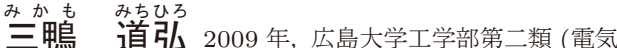
電子工学課程) 卒業. 2011 年, 同大学院工学研究科情報 工学専攻博士課程前期修了. 2011 年, 同大学院工学研究 科情報工学専攻博士課程後期入学. 現在, コンピュータ グラフィックスの研究に従事. 学生会員.

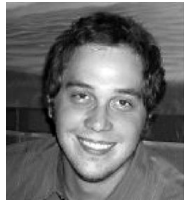

Marcos Slomp 2005 年, Universidade Federal do Rio Grande do Sol (UFRGS, Brazil) (Computer Science) 卒業. 2007 年, Institute of Informatics (Computer Science) Master Course 修了. 2012 年, 広島大学大学院工学研究科情報工学専攻博士課程後 期修了. 現在, 鹿児島大学工学部情報生体システム工学 科特任助教. 博士 (工学).

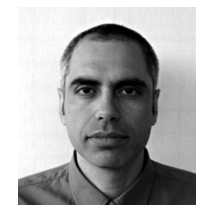

Bisser Raytchev 2000 年，筑波大学大学院 工学研究科電子情報専攻博士課程修了. 2000 年, NTT コミュニケーションサイエンス研究所研究員. 2003 年, 産業技術総合研究所情報技術研究部門博士研究員. 2008 年, 広島大学大学院工学研究院助教. 現在に至る. 画像 認識, コンピュータビジョンの研究に従事. 博士 (工学).

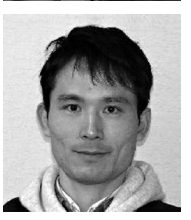

态末ぎ攏る 1996 年, 名古屋大学工学部情報工学 科卒. 1996 年, 同大学院工学研究科情報工学専攻博士 課程前期修了. 2001 年, 同専攻博士課程後期修了. 現 在, 広島大学大学院工学研究院准教授. 画像認識, コン ピュータビジョンの研究に従事. 博士 (工学). 正会員

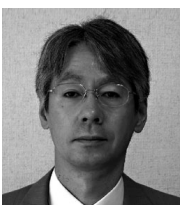

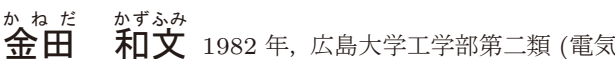
系) 卒業. 1984 年, 同大学院博士課程前期修了. 1986 年, 同大学工学部助手. 1991 年, 米国ブリガムヤング大 学客員研究員. 2004 年, 広島大学大学院工学研究院教 授.コンピュータグラフィクス，ビジュアライゼーショ ンなどの研究に従事. 工学博士. 